\title{
PENINGKATAN PROSES DAN HASIL BELAJAR MUATAN IPA TEMA 8 SUBTEMA 1 DENGAN MENGGUNAKAN PENDEKATAN SAINTIFIK MODEL PROBLEM BASED LEARNING (PBL)
}

\author{
Irwan Bayu Prasetyo ${ }^{1}$, Nyoto Harjono ${ }^{2}$, Gamaliel Septian Airlanda ${ }^{3}$ \\ 1,2,3 Jurusan Pendidikan Guru Sekolah Dasar, FKIP \\ Universitas Kristen Satya Wacana \\ Salatiga, Indonesia \\ email : 292014227@student.uksw.edu1 , har.john59@gmail.com², \\ gama.airlanda@staff.uksw.edu ${ }^{3}$
}

\begin{abstract}
Abstrak
Tujuan penelitian ini adalah untuk menerapkan model Problem Based Learning untuk meningkatkan proses dan hasil belajar pada muatan IPA Tema 8 Sub Tema 1 pada siswa kelas 4 SD. Penelitian dilaksanakan pada tanggal 15 maret sampai dengan 5 april 2018. Jenis penelitian ini adalah Penelitian Tindakan Kelas dengan populasi penelitian adalah seluruh siswa SD Negeri Payungan 01 Kecamatan Kaliwungu Kabupaten Semarang dan sampel penelitian adalah siswa kelas 4 SD Negeri Payungan 01. Persentase hasil observasi aktivitas guru mengalami peningkatan dari pra siklus $73,8 \%$ menjadi $88 \%$ pada siklus 1 dan $93 \%$ pada siklus 2 . Aktivitas siswa mengalami peningkatan dari prasiklus dengan persentase $66,6 \%$ menjadi $85 \%$ pada siklus 1 dan $93 \%$ pada siklus 2. Hasil belajar siswa pada pra siklus siswa tuntas berjumlah 11 siswa dengan persentase $55 \%$ dan tidak tuntas 9 siswa dengan persentase $45 \%$. Setelah melakukan perbaikan siklus I terjadi peningkatan ketuntasan yaitu 15 siswa tuntas dengan persentase $75 \%$ dan siswa tidak tuntas dengan persentase $25 \%$, hasil dari perbaikan siklus 1 belum mencapai indikator yakni $90 \%$ ketuntasan, maka dilaksanakan perbaikan siklus 2 . Setelah pelaksanaan siklus 2 terjadi peningkatan ketuntasan yakni 19 siswa tuntas dengan persentase 95\% sedangkan siswa yang tidak tuntas berjumlah 1 dengan persentase $5 \%$. Dengan demikian pendekatan saintifik dengan model pembelajaran PBL dapat meningkatkan proses dan hasil belajar siswa kelas 4 SD.
\end{abstract}

Kata Kunci : Pendekatan Saintifik, Model Pembelajaran Problem Based Learning, Proses dan Hasil Belajar

\begin{abstract}
The purpose of this research is to apply Problem Based Learning model to improve process and learning outcomes on the content of IPA Theme 8 Sub Theme 1 in grade 4 elementary school. The study was conducted on 15 March to 5 April 2018. This research type is Classroom Action Research with study population is all students of SD Negeri Payungan 01 District Kaliwungu Semarang Regency and the sample of research is 4th grade students of SD Negeri Payungan 01. Percentage of teacher observation result increase from pre cycle $73,8 \%$ to $88 \%$ in cycle 1 and $93 \%$ in cycle 2. Student activity increased from pre-cycle with percentage of $66,6 \%$ to $85 \%$ in cycle 1 and $93 \%$ in cycle 2. Student learning outcomes in pre-cycle of complete students amounted to 11 students with $55 \%$ percentage and not complete 9 students with a percentage of $45 \%$. After improving cycle 1 , there are 15 students completing with $75 \%$ percentage and the student is not complete with $25 \%$ percentage, the result of the improvement of cycle 1 has not reached the indicator that is $90 \%$ completeness, then the cycle 2 is implemented. After the implementation of cycle 2 there is an increase in mastery of 19 students complete with a percentage of $95 \%$ while students who do not complete amounted to 1 percentage of $5 \%$. Thus the scientific approach with the learning model of $P B L$ can improve the process and the results of learning grade 4 elementary school.
\end{abstract}

Keywords: Scientific Approach, Problem Based Learning Model, Learning Process and Results 


\section{Pendahuluan}

Dalam Permendikbud No.22 Th. 2016 tentang standar proses mengemukakan bahwa proses pembelajaran pada satuan pendidikan diselenggarakan secara interaktif, inspiratif, menyenangkan, menantang, memotivasi siswa untuk berpartisipasi aktif, serta memberikan ruang yang cukup bagi prakarsa, kreativitas, dan kemandirian sesuai dengan bakat, minat, dan perkembangan fisik serta psikologis siswa.

Dari observasi yang dilakukan di SD Negeri Payungan 01, proses pembelajaran khususnya IPA (gaya dan gerak) masih diselenggarakan secara konvensional, yaitu proses pembelajaran yang dilakukan masih berpusat pada guru. Sehingga siswa pasif dan hasil belajar muatan IPA pada siswa tergolong masih rendah. Hal ini terbukti dari beberapa kali mengerjakan soal tes kecil, pencapaian ketuntasan belajar siswa sangat rendah, yaitu dari 20 siswa yang terdiri dari 8 siswa laki-laki dan 12 siswa perempuan, baru 9 siswa atau (45\%) yang telah tuntas belajar dan 11 peserta didik (55\%) belum tuntas.

Agar dalam proses pembelajaran siswa menjadi aktif, maka guru harus pintar memilih pendekatan dan model yang sesuai dengan kondisi siswa. Salah satu pendekatan yang sesuai adalah pendekatan saintifik, yang mana pendekatan saintifik adalah pendekatan ilmiah yang diterapkan dalam kurikulum 2013. Menurut Imas Kurniasih (2014:29) pembelajaran dengan pendekatan saintifik adalah proses pembelajaran yang dirancang sedemikian rupa agar peserta didik secara aktif mengonstruksi konsep, hukum atau prinsip melalui sebuah tahapan-tahapan. Sedangkan model yang digunakan adalah model pembelajaran Problem Based Learning (PBL).

Menurut Cahyo (2013:283) model pebelajaran PBL adalah suatu model pembelajaran yang didasarkan pada prinsip menggunakan masalah sebagai awal akuisisi dan integrasi pengetahuan baru. Sehingga siswa dapat mengembangkan ketrampilan menyelesaikan masalah serta membangun pengetahuan baru. Kelebihan model pembelajaran PBL adalah pembelajaran berpusat pada siswa, realistik dengan kehidupan siswa, dan dapat memupuk sifat inkuiri siswa (Triyanto, 2011:96-97). Dengan diterapkanya pendekantan saintifik dengan model pembelajaran PBL, diharapkan dapat meningkatan proses dan hasil belajar muatan IPA (gaya dan gerak) siswa kelas 4 SD Negeri Payungan 01.

\section{Metode}

Jenis penelitian ini adalah Penelitian Tindakan Kelas. Penelitian ini dilaksanakan di kelas 4 SD Negeri Payungan 01 Kecamatan Kaliwungu Kabupaten Semarang semester 2 tahun pelajaran 2017/2018. Populasi penelitian ini adalah seluruh siswa SD Negeri Payungan 01 Kecamatan Kaliwungu Kabupaten Semarang. Variabel bebas dalam penelitian ini adalah pendekatan saintifik dengan model PBL, sedangkan variabel terikat adalah proses dan hasil belajar.

Teknik pengumpulan data menggunakan teknik observasi, dokumentasi, dan tes. Observasi digunakan untuk mengamati perilaku guru dan siswa selama proses pembelajaran berlangsung, dokumentasi digunakan untuk memperoleh data siswa berupa rapor siswa sebagai pengukur kinerja siswa selama proses pembelajaran sebelumnya., dan tes digunakan sebagai alat ukur hasil belajar siswa.

Teknik analisis data yang digunakan dalam penelitian ini, adalah teknik deskriptif komparatif. Teknik deskriptif komparatif adalah teknik yang membandingkan hasil belajar pada muatan IPA antar siklus yang meliputi ketuntasan hasil belajar dengan KKM $\geq 65$, skor minimum, skor maksimum dan skor rata-rata pra siklus, siklus 1, dan siklus 2 .

Penelitian yang digunakan dalam tulisan ini yaitu Penelitian Tindakan Kelas (PTK). PTK ini, mengacu pada teori Kemmis dan Taggart dalam Suwarsih Madya (2006:10). PTK merupakan pemberian cara kerja yang melibatkan teori dan praktik menjadi suatu kesatuan yang utuh. Rencana dari penelitian ini menggunakan model spiral Kemmis dan Taggrat dengan menggunakan 2 siklus. Setiap siklus terdapat 3 tahap yaitu, perencanaan, tindakan 
dan observasi, dan refleksi. Tindakan dalam hal ini pelaksanaan rencana pembelajaran implementasi RPP dan observasi, serta Refleksi.

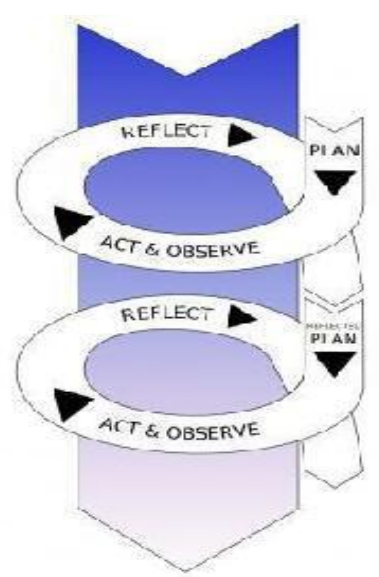

Gambar 1. Model Spiral Menurut C. Kemmis dan Mc. Taggrat

\section{Hasil dan Pembahasan}

Penelitian yang dilakukan sesuai dengan model Problem Based Learning dengan metode saintifik dilaksanakan dalam dua siklus, setiap siklus terdiri dari dua pertemuan.

Analisis rata-rata hasil perbandingan proses pembelajaran guru dan siswa kelas 4 SD Negeri Payungan 01 dari kondisi pra siklus, siklus 1, dan siklus 2 mengalami peningkatan. Hasil perbandingan analisis rata-rata observasi guru dan siswa dapat dilihat pada tabel 1 berikut.

Tabel 1. Perbandingan Analisis Rata-rata Observasi Pra siklus, Siklus 1 dan Siklus 2

\begin{tabular}{cccccccc}
\hline No & $\begin{array}{c}\text { Ketuntasan } \\
\text { Belajar }\end{array}$ & $\begin{array}{c}\text { Rata- } \\
\text { rata }\end{array}$ & presentase & $\begin{array}{c}\text { Rata- } \\
\text { rata }\end{array}$ & Presentase & $\begin{array}{c}\text { Rata- } \\
\text { rata }\end{array}$ & presentase \\
\hline 1. & $\begin{array}{c}\text { Aktivitas } \\
\text { Guru }\end{array}$ & 65 & $73,8 \%$ & 78 & $88 \%$ & 82 & $93 \%$ \\
2. & $\begin{array}{c}\text { Aktivitas } \\
\text { Siswa }\end{array}$ & 32 & $66,6 \%$ & 41 & $85 \%$ & 45 & $93 \%$ \\
\hline
\end{tabular}

Berdasarkan tabel 1 tentang perbandingan analisis rata-rata skor observasi aktivitas guru dan siswa terjadi peningkatan dari pra siklus 1 ke siklus 2 dengan penerapan model pembelajaran PBL. Setelah pelaksanaan tindakan siklus 1 rata-rata skor aktivitas guru mencapai 78 dengan persentase $88 \%$ meningkat menjadi 82 dengan persentase 93\%. Selanjutnya rata-rata skor aktivitas siswa pada siklus 1 dengan hasil rata-rata 41 dengan persentase $85 \%$, kemudian pada siklus 2 rata-rata skor meningkat menjadi 45 dengan persentase $93 \%$. Berikut perbandingan rata-rata hasil analisis skor observasi aktivitas guru dan siswa pada pra siklus, siklus 1 , siklus 2 dapat disajikan pada diagram 1 sebagai berikut. 


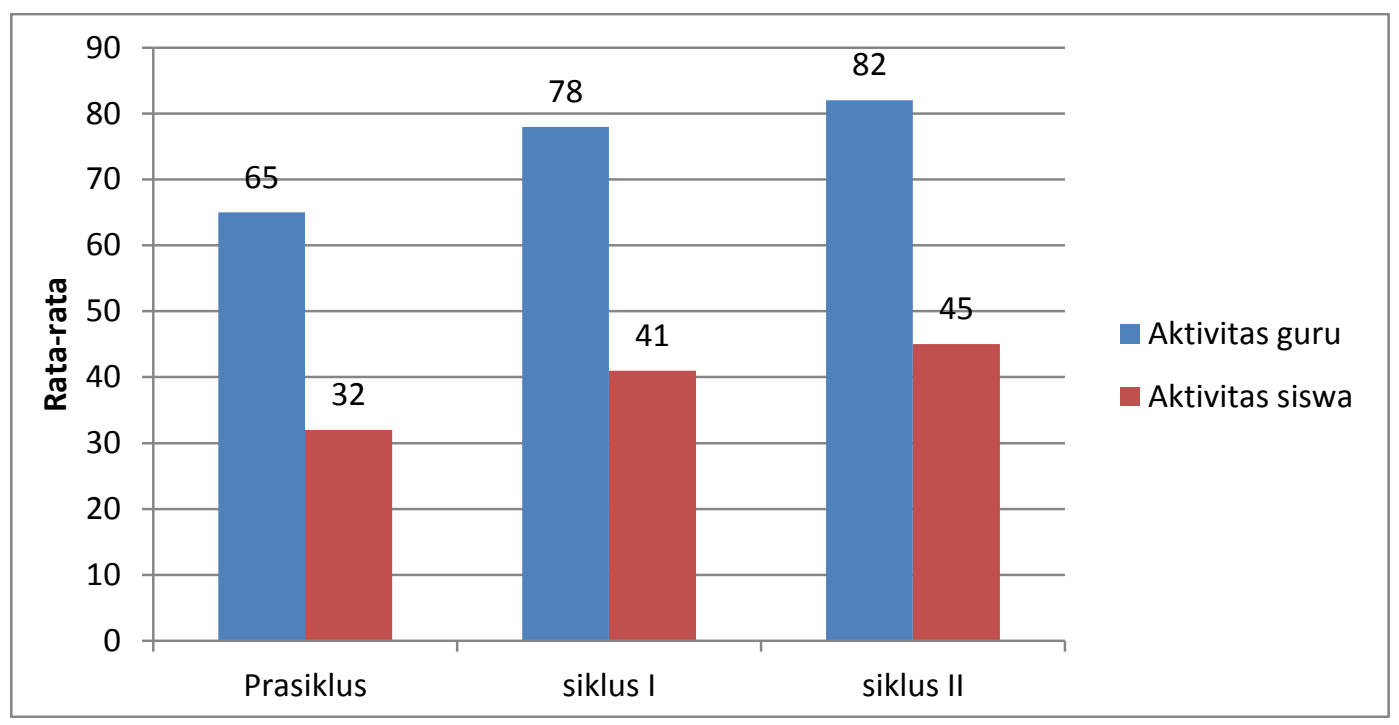

Diagram 1. Diagram Peningkatan Rata-rata Skor Observasi Pra siklus, Siklus I dan Siklus II

Peningkatan proses pembelajaran mempengaruhi hasil belajar siswa. Peningkatan hasil belajar siswa dapat dilihat pada tabel perbandingan ketuntasan berikut.

Tabel 2. Perbandingan Ketuntasan Belajar IPA Pra siklus, Siklus 1, Dan Siklus 2

\begin{tabular}{|c|c|c|c|c|c|c|c|c|}
\hline \multirow[t]{2}{*}{ No. } & \multirow{2}{*}{$\begin{array}{c}\text { Ketuntasan } \\
\text { Belajar }\end{array}$} & \multirow{2}{*}{$\begin{array}{c}\text { Nilai } \\
(\mathrm{X})\end{array}$} & \multicolumn{2}{|c|}{ Pra siklus } & \multicolumn{2}{|c|}{ Siklus 1} & \multicolumn{2}{|c|}{ Siklus 2} \\
\hline & & & Jumlah & $\%$ & Jumlah & $\%$ & Jumlah & $\%$ \\
\hline 1. & Tuntas & $\geq 65$ & 11 & 55 & 15 & 75 & 19 & 95 \\
\hline 2. & Belum Tuntas & $\leq 65$ & 9 & 45 & 5 & 15 & 1 & 5 \\
\hline & Nilai Tertinggi & & \multicolumn{2}{|c|}{73} & \multicolumn{2}{|c|}{87} & \multicolumn{2}{|c|}{97} \\
\hline & Nilai Terendah & & \multicolumn{2}{|c|}{43} & \multicolumn{2}{|c|}{57} & \multicolumn{2}{|c|}{63} \\
\hline & Nilai Rata-rata & & \multicolumn{2}{|c|}{61,65} & \multicolumn{2}{|c|}{72} & \multicolumn{2}{|c|}{80,05} \\
\hline
\end{tabular}

Berdasarkan tabel 2 tentang perbandingan rata-rata hasil belajar IPA dapat di ketahui adanya peningkatan pada nilai rata-rata dari pra siklus, siklus 1 , siklus 2 . Pada siklus 1 nilai rata-rata kelas 72 yang pada pra siklus sebesar 61,65, sedangkan pada siklus 2 perolehan nilai rata-rata menjadi 80,05 . Dengan demikian peningkatan pembelajaran dengan model problem based learning dengan metode saintifik dapat dikatakan berhasil karena hasil belajar mencapai tujuan yakni presentase 95\%. Berikut perbandingan nilai rata-rata ketuntasan belajar muatan IPA siswa kelas 4 SD Negeri Payungan 01 pada pra siklus, siklus 1 , siklus 2 dapat disajikan pada diagram 2 sebagai berikut. 


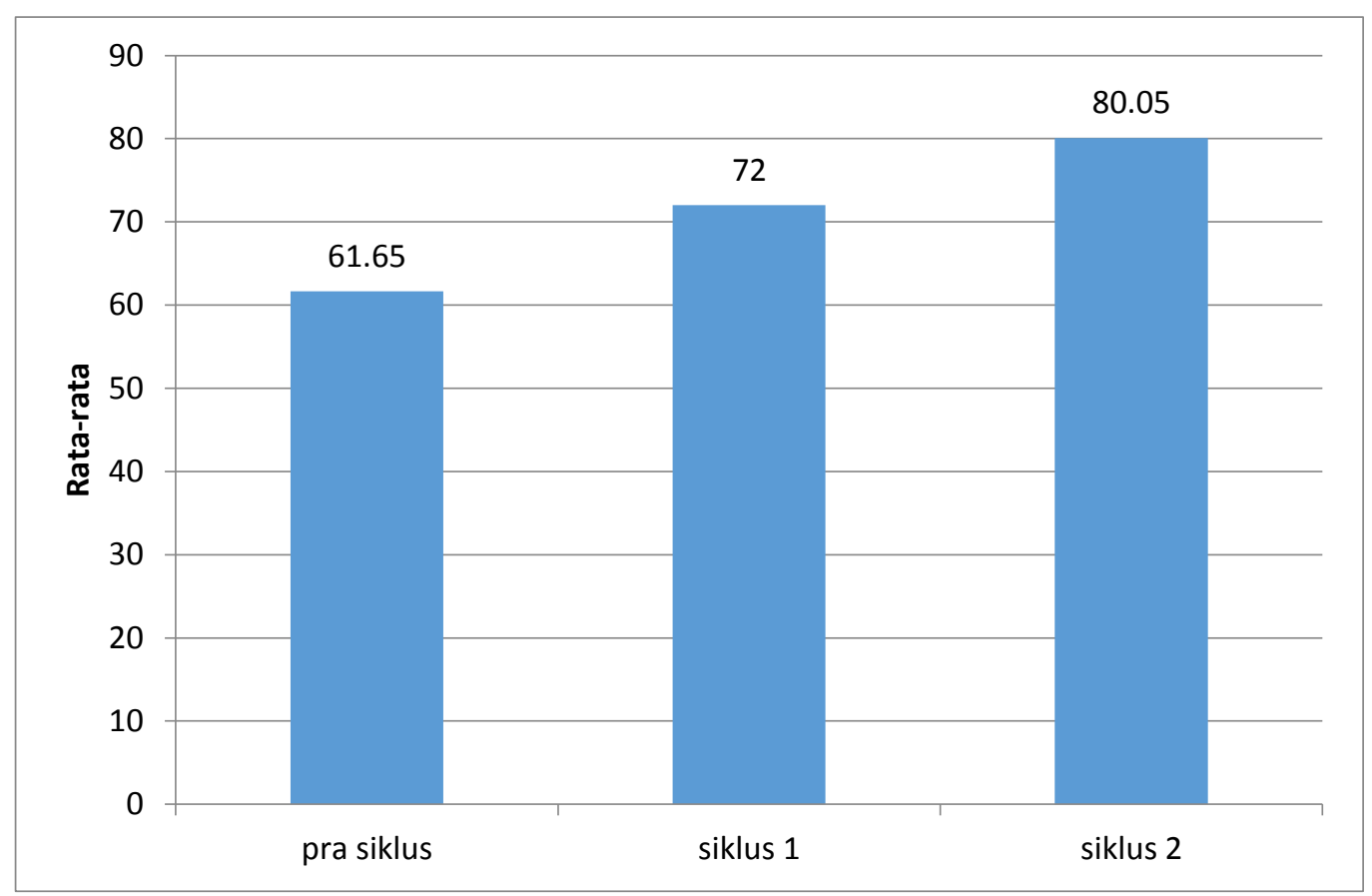

Diagram 2. Peningkatan Rata-rata Hasil Belajar IPA Pra siklus, Siklus 1, dan Siklus 2

Hasil observasi sebelum diberikan tindakan dengan menggunakan pendekatan saintifik model PBL pada siswa kelas 4 SD Negeri Payungan 01 Kecamatan Kaliwungu Kabutaten Semarang semester 2 tahun pelajaran 2017/2018 diperoleh data bahwa hasil belajar siswa pada muatan IPA masih rendah, sebanyak 45\% dari 20 siswa atau 11 siswa sudah mencapai KKM yang ditetapkan sebesar 65, sedangkan 55\% dari 20 siswa atau 9 siswa belum mencapai KKM yang ditetapkan. Hal ini disebabkan oleh pembelajaran yang digunakan oleh guru masih bersifat konvensional (pembelajaran masih berpusat pada guru) sehingga interaksi antara siswa yang satu dengan siswa yang lainnya masih kurang.

Setelah dilakukan penelitian dengan menggunakan model pembelajaran PBL (Problem Based Learning) untuk mengatasi rendahnya hasil belajar muatan IPA siswa kelas 4 SD Negeri Payungan 01 Kecamatan Kaliwungu Kabutaten Semarang semester 2 tahun pelajaran 2017/2018 menunjukkan adanya peningkatan keaktifan dalam proses pembelajaran dan hasil belajar muatan IPA pada siswa. Pada siklus 1 menunjukan peningkatan ketuntasan hasil belajar muatan ipa sebesar $20 \%$ dibandingkan tahapan pra siklus. Pada tahapan pra siklus siswa yang tuntas belajar sebanyak 55\% Sedangkan tahapan siklus 1 jumlah siswa yang tuntas belajar meningkat menjadi $75 \%$. Karena hasil yang diharapkan belum memenuhi indikator kinerja sebesar $90 \%$ dari keseluruhan siswa kelas 4, maka peneliti mengadakan tindakan siklus 2. Berdasarkan kekurangan pada siklus 1 peneliti melakukan perbaikan pada tindakan siklus 2. Pada siklus 2 menunjukan peningkatan ketuntasan belajar sebesar $95 \%$ dari sebelumnya $75 \%$ pada tahapan siklus 1 . Dengan demikian indikator kinerja yang ditetapkan peneliti sudah tercapai.

Berdasarkan analisis data yang telah dilakukan, pendekatan saintifik dengan menggunakan model PBL dapat meningkatkan keaktifan siswa dalam proses pembelajaran. Dengan demikian hasil belajar siswapun juga meningkat. Dari pemberian perlakuan pendekatan saintifik dengan menggunakan model PBL terbukti dalam pra siklus, siklus 1, dan siklus 2 hasil belajar siswa selalu meningkat.

Berdasarkan uraian penelitian yang telah disajikan, maka penggunaan model PBL dengan metode saintifik dalam pembelajaran muatan IPA kelas 4 SD Negeri Payungan 01 tahun pelajaran 2017/2018 selaras dengan penelitian yang telah dilakukan oleh Rismaerista Rini dan Mawardi dengan judul Penerapan Keterampilan Proses Saintifik dan Hasil Belajar Siswa Kelas 4 SDN Slungkep 02 Tema Peduli Terhadap Makhluk Hidup Menggunakan 
Model Problem Based Learning, dari penelitian yang dilakukan diketahui hasil belajar siswa meningkat pada siklus $170 \%$ dan pada siklus $287 \%$. Hal ini menunjukkan bahwa keberhasilan hasil belajar siswa meningkat $87 \%$ dengan penerapan model Problem Based Learning.

\section{Simpulan dan Saran}

Berdasarkan hasil penelitian yang telah dilakukan dapat disimpulkan bahwa, pendekatan saintifik dengan menggunakan model pembelajaran Problem Based Learning dapat meningkatkan proses dan hasil belajar muatan IPA siswa kelas 4 SD Negeri Payungan 01 Kecamatan Kaliwungu Kabutaten Semarang semester 2 tahun pelajaran 2017/2018. Hal ini dapat dilihat pada peningkatan hasil belajar yang signifikan yakni siswa yang tuntas pada pra siklus, siklus I, siklus II adalah 55\%, 75\%, 95\%. Skor minimal pada prasiklus, siklus I, siklus II adalah $43,57,63$. Skor maksimal pada prasiklus, siklus I, siklus II adalah 73, 87, 97. Rata-rata pada pra siklus, siklus I, siklus II adalah 61,65, 72, 80,05. Penelitian ini dikatakan berhasil karena hasil penelitian menunjukkan ketuntasan belajar yaitu $95 \%$ lebih besar dari indikator kenerja yaitu $90 \%(95 \% \geq 90 \%)$, dan skor rata-rata kelas sebesar 80,05 dapat dikatakan telah mencapai KKM yang telah ditetapkan yaitu 65 $(80,05 \geq 65)$.

Dari hasil penelitian yang telah dilaksanakan, saran yang dapat diberikan guna meningkatkan kualitas pembelajaran adalah sebagai berkut.

Guru dapat menggunakan pendekatan saintifik melalui model PBL dalam pembelajaran, dan guru dapat mengembangkan berbagai model pembelajaran inovatif yang mampu menciptakan suasana pembelajaran yang menyenangkan, supaya siswa lebih antusias dalam mengikuti pembelajaran tanpa guru membedakan tingkat kemampuan siswa.

Bagi Sekolah, Sekolah sebagai lembaga pendidikan harus memantau kegiatan pembelajaran yang dilaksanakan oleh guru, agar diketahui seberapa efektif model pembelajaran yang telah diterapkan. Penerapan pendekatan saintifik dan model pembelajaran yang inovatif dalam pelaksanaannya dapat dijadikan refrensi sebagai upaya untuk memperbaiki mutu dan kualitas pembelajaran.

Bagi Siswa, Siswa harus dapat memotivasi diri sendiri agar dapat menyelesaikan suatu permasalahan dalam kehidupan sehari-hari yang berkaitan dengan konsep dasar IPA melalui pembelajaran yang menggunakan model yang inovatif maka siswa lebih tertarik mengikuti pembelajaran sehingga hasil belajar siswa meningkat.

\section{Daftar Rujukan}

Aly, Abdullah dan Eny Rahma. 2011. Ilmu Alamiah Dasar. Jakarta: PT Bumi Aksara.

Cahyo, Agus N. 2013. Panduan Aplikasi Teori-teori Belajar Mengajar. Jogjakarta: Diva Press.

Evans, James R. dan William M. Lindsay. 2007. An Introduction to Six Sigma and Process Improvement. Jakarta : Salemba Empat.

Dimyati, Mudjiono. 2013. Belajar dan Pembelajaran. Jakarta: Rineka Cipta.

Hosnan.2014. Pendekatan Saintifik Dan Kontekstual Dalam Pembelajaran Abad 21. Bogor: Ghalia Indonesia.

Kurniasih, Imas dan Sani, Berlin. 2014. Sukses Mengimplementasikan Kurikulum 2013. Jakarta: Kata Pena. 
Majid, Abdul. 2014. Pembelajaran Tematik Terpadu. Bandung: PT Remaja Rosdakarya.

Ngalimun. 2014. Startegi dan Model Pembelajaran. Yogjakarta: Aswaja Pressindo.

Peraturan Menteri Pendidikan dan Kebudayaan Republik Indonesia Nomor 65 Tahun 2013 tentang Standar Proses Pendidikan Dasar dan Menengah. 2013. Jakarta.

Rini, Rismaerista. 2015. Penerapan Keterampilan Proses Saintifik dan Hasil Belajar Siswa Kelas 4 SDN Slungkep 02 Tema Peduli Terhadap Makhluk Hidup Menggunakan Model Problem Based Learning. Skripsi. Jurnal Scholaria Universitas Kristen Satya Wacana (UKSW).

Sudjana, Nana. 2010. Penilaian Hasil Proses Belajar Mengajar. PT. Remaja Rosdakarya. Bandung. $168 \mathrm{hlm}$.

Susanto, Ahmad. 2013. Teori Belajar dan Pemebelajaran Di Sekolah Dasar. Jakarta. Kencana Pernada Media Groub.

Sutirna, 2012. Perkembangan dan Pertumbuhan Peserta Didik. Bandung: CV. Andi Offset.

Trianto. 2011. Model-Model Pembelajaran Inovatif Berorientasi Kontruktivistik. Jakarta: Prestasi Pustaka.

Undang-undang Republik Indonesia Nomor 20 Tahun 2003 Tentang Sistem Pendidikan Nasional.

Wardani, Naniek dkk. 2012. Asesmen Pembelajaran SD. Salatiga: Widia Sari. 